ends-and when they touch, weld together, and their surfaces become metallic, like graphite.

Diamonds heated in charcoal tubes were suddenly changed and became conductors. Still more remarkable effects were produced when he used collaterally with the 600 Bunsens 135 Muncké with zincs $13 \frac{3}{4} \mathrm{in}$. high and $19 \frac{2}{3}$ in. wide. With these sugar-charcoal was volatilised immediately.

I think it may be inferred from these facts that even at the temperature of a powerful electric arc enough charcoal vapour may be present to form its spectrum, and there is little doubt that the temperature of discharge of a good inductorium combined with a sufficient condenser is still hotter than the arc.

It is to be noticed that Despretz in these experiments anticipated Dr. Siemens's electric furnace. He mentions that he fused $375^{\circ}$ grains of platinum in a few minutes, and could have done more had he had a larger crucible.

\section{A Case of Fascination}

Some years ago it was my fortune to witness a case of "fascination" between a large striped snake and a medium-sized toad. When first seen they were about fifteen inches apart. The snake lay in a coil with its head thrust out towards its victim, and moving slowly, its eyes glittering and its tongue darting incessantly.

The toad was standing on the very tips of its claws, with its limbs rigidly drawn up to their full length, its eyes fixed upon its captor and fairly bursting from their sockets, its mouth covered with foam, and its whole body swaying to and fro, and seeming just ready to pitch forward upon its face.

The movement of the snake became more and more rapid, and the agitation of the toad more intense, until the space between them was reduced to some three or four inches, when the snake opened wide its mouth, and the laboured breathing of its victim stopped short in a low guttural moan.

At this point my own agitation became so great that, seizing a heavy stone, I finished the snake at one blow. The instant the snake was struck the toad fell backward as suddenly as though itself had been hit, and lay upon its back for some minutes with no signs of life. At length it gained its feet and began to creep languidly away.

Lyons, N.Y., January is

J. T. BROWNELL

\section{Birds Laying in January}

As a proof of the unusual mildness of the weather just previous to the intense frost and severe snowstorms most parts of the country have lately been suffering from, it may interest some of your readers to learn that not far from this place, on the $13^{\text {th }}$ Jan., a wren's nest with seven eggs in it, quite fresh, was taken. The nest I have in my possession, and it bears every evidence of having been lately tenanted. The eggs, I am sorry to say, are broken; they were placed in a cup for safety, and were most unfortunately knocked down when the room was dusted, giving however unmistakable prosf of their having been but lately laid.

I do not know whether there is any instance on record of a wren's nest having been found in January before.

\section{JOHN H. WILLMORE}

Queenwood College, near Stockbridge, Hants, January 28

\section{Vibration of Telegraph Wires during Frost}

While walking with my son by the Liverpool, Crosby, and Southport Railway between Crosby and Hall Roait stations he called my attention to the telegraph wires, which were in a state of rapid vibration. The day was frosty, the time Ir.3o a.m., and the sun, which had been showing us a bright disk through the haze was beginning to throw out rays and shine a little strongly. At first I thought the movement must be only apparent -a mere optical delusion-as the air was perfectly calm. A closer examination convinced me to the contrary, as the under part of the wires were covered with pendant ice needles, a sort of rime, which moved to and fro indicating a torsional or twisting vibration of the wires, and as the rapidity of the vibrations decreased this was more clearly seen. In about five minutes the movement ceased, and $I$ have not noticed it since, though I have frequently passed under the wires on my way to skate. Can any of your correspondents account for the phenomenon? It appeared as if in some way connected with previous contraction by the frost and sudden expansion in jerk; by the sun's rays. My son informs me that two years ago, during a frost, he noticed the strained wires of a garden-fence behaving in the same curious way.

Park Corner, Blundellsands

T. Mellard Reade

\section{"Mock Sun"}

I SEND a sketch of a parhelion which I saw from the East Cliff, Hastings, on Thursday, January 20, at 3 p.m. The crescents above the sun were fairly bright and well developed, and there were faint traces of a second ring outside, and some distance from, the first.

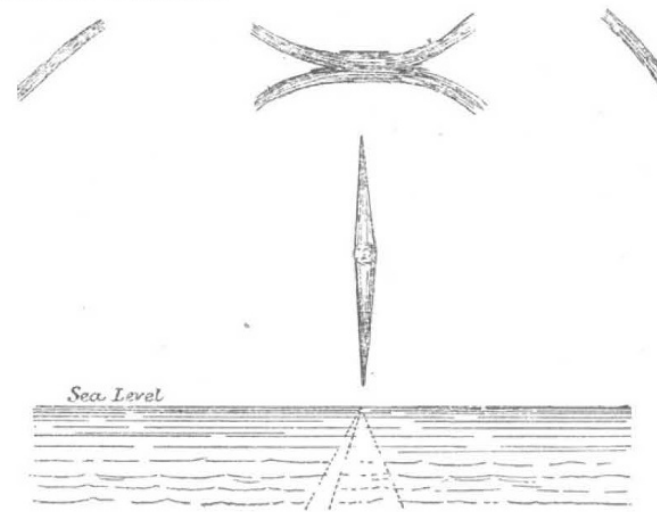

There was a slight fog at the time, with a north-east wind and hard frost, which has continued up to this time. We have had no snow here since that "terrible Tuesday," the 18 th.

I do not remember ever having seen this phenomenon before, except in pictures of the Arctic Regions.

St. Leonards, January 24

J. E. H. Peyton

\section{ON SOME RECENT CHARTS AND MAPS OF CURVES OF EQUAL MAGNETIC VARIATION OR DECLINATION}

SINCE the year I7or, when Halley published his famous chart showing curves of equal magnetic variation for the Atlantic and Indian Oceans, the construction of similar charts, amended and enlarged as data increased, has been of great interest to magnetic science and of practical value to the navigator.

Halley's chart of I7or was expanded to embrace the navigable parts of the whole world, and brought up to the epoch 1756 by Mountaine and Dodson, whose labours were followed by those of Churchman in 1794, Yeates in I8I7, and Hansteen (for several distinct epochs between 1600 and 1787 ) in 1819 . In 1833 Barlow's chart, together with curves for the North Polar regions, accompanied a descriptive paper in the Phil. Trans. for that year.

In I840 Gauss and Weber's charts of theoretical curves of the three magnetic elements for the whole world, including special Polar charts, were published. These curves were culculated on the basis of a mathematical theory founded upon a large number of observations fairly distributed over the surface of the globe.

About this latter period the practice of ascertaining the errors of the compass on shipboard (as due to the effects of iron) for every ship in the Royal Navy, at certain periods and on change of magnetic latitude, was established by the Admiralty on the recommendation of a compass committee specially appointed to consider the question of compass efficiency and management. This, as bearing on the subject under review, was an important step towards obtaining reliable data for the construction of Variation charts now becoming so essential an element in navigation.

Following on this, Archibald Smith's mathematical investigations of the theory of the deviations of the compass on board ship enabled Sabine to correct observations made in the Atlantic and the Antarctic Oceans 
with great precision. The charts accompanying Sabine's "Contributions to Terrestrial Magnetism," No. ix. (Phil. Trans. 1849), were among the earliest on which the data whence the curves were drawn are recorded, although it may be observed that even a portion of the observations made at sea and utilised in these charts had no corrections applied to them for the effects of the ship's iron.

Considering the local magnetic disturbance found to exist on land in many regions and the large area of watercovered portions of the globe, observations made at sea, when systematically carried out and corrected for local attraction in the ship, have become an important factor in ascertaining the magnetic variation for the use of navigators at any given epoch.

Evans's Variation chart for the epoch 1858 , embracing the navigable parts of the world, and in which the whole of the observations made at sea were corrected for the effects of the ship's iron, was published by the Admiralty. A further advance on Variation charts of an earlier date was the addition to this of a map showing the amount of annual change of the variation as determined at several localities, enabling reductions for the succeeding ten years to be made with a reasonable approach to the truth.

The increase of iron-built and composite vessels in late years has rendered a reliable Variation chart a necessary adjunct to navigation. This object appears to have been kept steadily in view by the Hydrographic Department of the Admiralty, for, in $187 \mathrm{I}$, a new edition of the "Variation Chart of the World," reduced to that epoch (with polar charts added) was published in continuation of the chart for 1858 . This chart was the result of the joint labours of Capt. Evans and a member of the compass department, Navigating-Lieut. Creak, R.N.

We have now to notice the more recent publications of these contributions to terrestrial magnetism. A chart of the curves for 1880 , in continuation of those for the epochs 1858 and 1871 , by Staff-Commander Creak, has been published by the Admiralty. In its construction the observations made during the voyage of H.M.S. Challenger (1872-76) have been introduced, and amongst results from other sources, specially those taken from Mr. A. Schott's papers on the secular change of the variation published as Appendix No. 8 to the U.S. Coast Survey Report for 1874 , and also as a preliminary publication to the Report for 1879 ; Dr. Thorpe's observations in the United States, made about the 4 oth parallel of latitude, and results from the maps of the excellent magnetic survey of a large portion of the Eastern Archipelago in I874 77, made by Dr. Rijckevorsel, have also been included.

As confined to special portions of the world a map of the United States for the epoch 1875 , constructed by Mr. J. E. Hilgard, Assistant U.S. coast and geodetic surveys, published in the American Fournal of Science for March, 1880, and illustrating an article on the subject of magnetic variation or declination, is of a high order of excellence.

In this map the curves, which show several flexures strictly pourtraying results arising from local disturbance, have been drawn for every degree of [equal] variation. The results are from observations made during the progress of the U.S. Coast Survey up to 1877 , also from about 200 observations made in the interior of the country under the direction of Mr. Hilgard, to which were added every available observation from the land and boundary surveys, as well as those of private observers. Many of these results having been obtained at different periods of time, have been reduced to the given epoch by means of Mr. A. Schott's paper on Secular Change before referred to.

Although in maps and charts covering large geographical areas the variation lines for the land portions are generally drawn in regular curves (and so far deviating from strict accuracy), whilst those for the larger sea areas are necessarily so done, still in delineating the magnetic features of a portion of a continent the system followed by Mr. Hilgard, as also by Lamont in his European surveys between 1850 and 1860 , commends itself for accuracy.

The late Prof. A. D. Bache, who took a personal interest in the study of terrestrial magnetism, bequeathed a fund for scientific research. The expenses of obtaining the 200 observations in the interior of the United States before mentioned, were defrayed by a grant from this fund.

\section{THE ZOOLOGICAL STATION AT NAPLES}

"WHAT is a zoological station?" is a question we have often heard asked when Dr. Dohrn's institution at Naples is under discussion. A "zoological station" (according to Dr. Dohrn), we may reply, is a kind of zoological garden for marine animals, or what is commonly called an "aquarium," only that, contrary to the usual practice at Brighton, Westminster, and elsewhere, the scientific element of the establishment is mostly cultivated instead of the popular branch, Such at least is the case under Dr. Dohrn's system, and also, we believe, in other zoological stations that have been formed after his example.

It must be recollected that the lower forms of organic life, to the study of which zoological stations, as thus described, are mainly devoted, are much more numerous than the vertebrata, and much less understood. Even in our own seas a vast amount remains to be done before our knowledge of the thousands of marine organisms which populate our waters and shores can be deemed to be anything like complete. Still more is this the case in the Mediterranean, where under a bright sky and burning sun the clear waters teem with animal life in all its varieties. It was no doubt the well-known productiveness of the coast of Naples and the facilities offered for dredging in its land-locked Bay that induced Dr. Dohrn to fix his "Zoological Station" in this quarter instead of planting it on the shores of his Fatherland.

After several years of incessant labour Dr. Dohrn has got his establishment into excellent working order, and, as will be seen by our advertisement pages, promises us after so much cultivation a rich and abundant harvest. The proper subject to take up when the publication of results was determined upon was obviously the Biology of the Bay of Naples. Great difficulties however beset the advance of this project. As regards the Fishes, the more highly-organised Crustaceans, the Mollusca, and some of the Colenterata and Echinodernata, it appeared possible for the students at the Zoological Station to avail themselves largely of the results arrived at by former workers. But when they proceeded to examine into the scattered literature in which the innumerable armies of Lower Crustaceans, Annelids, Nemertians, Planarians, Nematodes, and such-like creatures are described, the case was very different. The ancient naturalists have mostly characterised their species in these groups in such vague diagnoses that it is impossible to identify them. Under such circumstances the students of the higher animals are accustomed to resort to the type-specimens whence the descriptions were taken in order to see what the authors really intended. But the impossibility of preserving many of the lower animals cuts this resource away from the marine zoologists, who have consequently contented themselves in some instances with referring their specimens to species never sufficiently described, in other cases with describing them as new. Hence has arisen a mass of confusion which can be only regarded as parallel to what existed among the more highly-organised animals in the ante-Linnean period. The transformations undergone by many of the lower marine animals and the extraordinary sexual differences add 